\title{
Complexation between Venlafaxine Hydrochloride and $\beta$-Cyclodextrin: Structural Study by Nuclear Magnetic Resonance Spectroscopy
}

\author{
Syed Mashhood Ali, ${ }^{*}$ Fahmeena Asmat, and Mamoru Koketsu ${ }^{\dagger}$ \\ Department of Chemistry, Aligarh Muslim University, Aligarh-202002 (VP), India. "E-mail: smashhoodali@yahoo.com \\ "Division of Instriment Analysis, Life Science Research Center, Gifu University, Gifu 501-1193, Japan \\ Received April 22, 2006
}

\begin{abstract}
$\Lambda$ detailed spectroscopic study ('II NMR, COSY, ROESY) of complexation of venlafaxine hydrochloride (VEN) with $\beta$-cyclodextrin $(\beta$-CD) was carried out in solution. The stoichiometry of the complex was determined to be $1: 1$ and penetration of aromatic ring into $\beta$-Cyclodextrin cavity was confirmed from primary rim side, with the help of ROESY spectral data. The structure of the venlataxine hydrochloride- $\beta$ CD complex has been proposed. The association constant was determined to be $234 \mathrm{M}^{-1}$.
\end{abstract}

Key Words : $\beta$-Cyclodextrin, Venlafaxine hydrochloride, Inclusion complexes, 'H NMR titration, ROESY

\section{Introduction}

Venlafaxine hydrochloride (VEN), commercially known as "Effexor" is a representative of a new class of antidepressants. It is a bicyclic phenylethyl amine and chemically unrelated to tricyclic, tetracyclic or other available antidepressant agents and designated as (R/S)-1-[2-dimethyl amino)-1-(4-methoxy phenyl)ethyl]cyclohexanol hydrochloride. This medication is used to treat anxiety. It acts by inhibiting selectively the uptake of serotonin and noradrenaline but shows no affinity for neurotransmitter receptors. Its solubility in water is $572 \mathrm{mg} / \mathrm{mL}^{\prime}$

CDs can be visualized as toroidal, hollow, truncated cones having highly hydrophilic surface and relatively hydrophobic cavity. ${ }^{2}$ By virtue of their shape and nature of cavity, CDs admit hydrophobic moieties into their cavity to form host-guest complexes. CDs have aroused considerable interest in the pharmaceutical field because of their potential to form complexes with a variety of drug molecules. ${ }^{3}$ Complexation of pharmaceutical compounds with CDs leads to alteration of physical, chemical and biological properties of guest molecules. The main advantages in the pharmaceutical use of CDs are the increase in solubility, improved stability of light and oxygen sensitive drugs. ${ }^{4}$

NMR spectroscopy, is one of the most sensitive methods for studying the inclusion phenomena, allowing one to determine not only the stoichiometry and stability of complexes but also the spatial relationships between hydrogen atoms of the CDs and the incorporated molecule. Although there are several techniques to predict the geometry of $\mathrm{CD}$ inclusion complexes, ${ }^{6}$ rotating frame NOE $(\mathrm{ROE})^{7}$ is the most reliable technique.

In continuation of our work on the preparation and structure elucidation of $\beta$-cyclodextrin inclusion complexes with pharmaceutical compounds, ${ }^{8.9}$ we report here our results on the detailed NMR spectroscopic study of $\beta-C D-$ venlafaxine hydrochloride inclusion complex in aqueous medium.

\section{Experimental Section}

'H NMR and 2D ROESY experiments were performed on a Bruker Advance DPX $400 \mathrm{MHz}$ spectrometer while COSY spectrum was recorded on a $800 \mathrm{MHz}$ Bruker instrument, in $\mathrm{D}_{2} \mathrm{O}$ at $25^{\circ} \mathrm{C}$. The 2D ROESY experiment was carried out under spin lock condition with a mixing time 500 ms. Chemical shift values, reported in $\delta(\mathrm{ppm})$, were calculated with reference to $\mathrm{HDO}$ signal at $4.790 .{ }^{1} \mathrm{H}$ NMR spectra for five samples of mixture of venlafaxine hydrochloride and $\beta$-CD were recorded keeping the concentration of $\beta C D$ constant at $20 \mathrm{mM}$ while the concentration of venlafaxine hydrochloride was varied from $8 \mathrm{mM}$ to $40 \mathrm{mM}$. Distinct peaks for complexed and uncomplexed form of VEN were not observed indicating rapid exchange of VEN between free and bind state on the NMR scale.

\section{Results and Discussion}

'H NMR spectra of venlafaxine hydrochloride, in the absence of $\beta-\mathrm{CD}$, exhibited a pair of doublets at $6.998(\mathrm{~J}=$ $8.8 \mathrm{~Hz})$ and $7.289(J=8.6 \mathrm{~Hz})$, each integrating for two protons. The signal at 7.289 exhibited through space interaction with $\mathrm{H}-7$ of methylene protons and was therefore assigned to $\mathrm{H}-3,5$ while that at 6.998 was ascribed to $\mathrm{H}-2,4$. The signals at 3.783 , integrating for 3 protons, and at 2.710 . integrating for 6 protons, were assignable to $-\mathrm{OCH}_{3}$ and $-\mathrm{N}\left(\mathrm{CH}_{3}\right)_{2}$ methyl groups, respectively. A pair of doublet of doublets at $3.547\left(J_{1}=4.0 \mathrm{~Hz}, J_{2}=13.2 \mathrm{~Hz}\right)$ and $3.041\left(J_{1}=\right.$ $4.0 \mathrm{~Hz}, J_{2}=12 \mathrm{~Hz}$ ), for one proton each, was due to H-7a and $\mathrm{H}-7 \mathrm{~b}$ protons. The signal for $\mathrm{H}-6$ appeared as a triplet at $3.688(J=12.4 \mathrm{~Hz})$. Cyclohexanol ring protons resonances appeared in the region $1.000-1.688$ and could not be determined.

An unambiguous resonance assignment for $\beta$-CD protons was made with the help of COSY spectrum (Figure 1). ${ }^{1} \mathrm{H}$ NMR spectra of mixture of venlafaxine hydrochloride and $\beta C D$ displayed significant upfield movements in the signals 


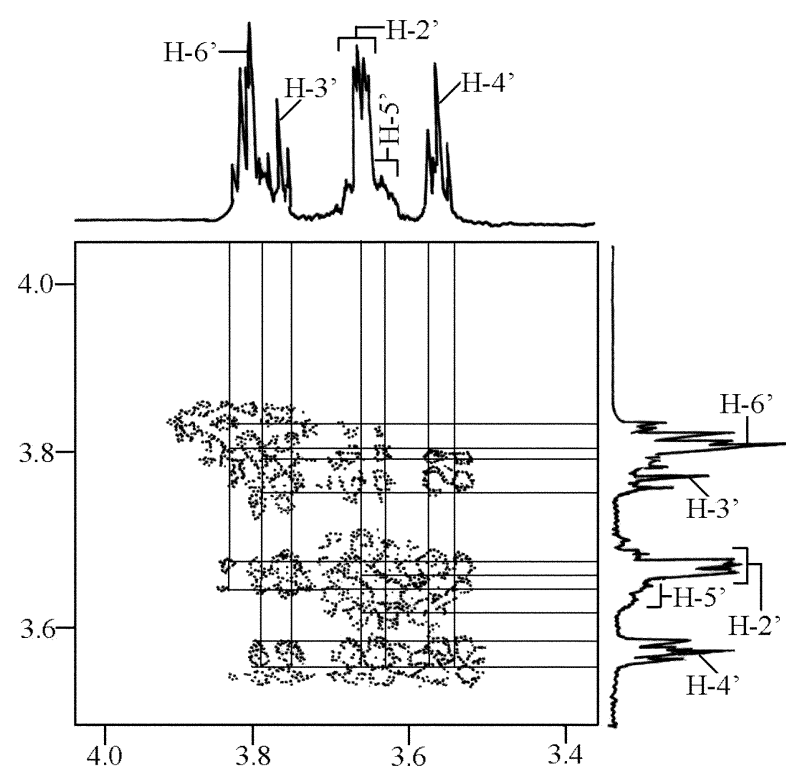

Figure 1. A section of COSY spectrum $(800 \mathrm{MHz})$ of the I : I mixlure of venlafaxine hydrochloride with $\beta C \mathrm{CD}$, in $\mathrm{D}_{2} \mathrm{O}$ ) at $25^{\circ} \mathrm{C}$ with $500 \mathrm{~ms}$ mixing time.

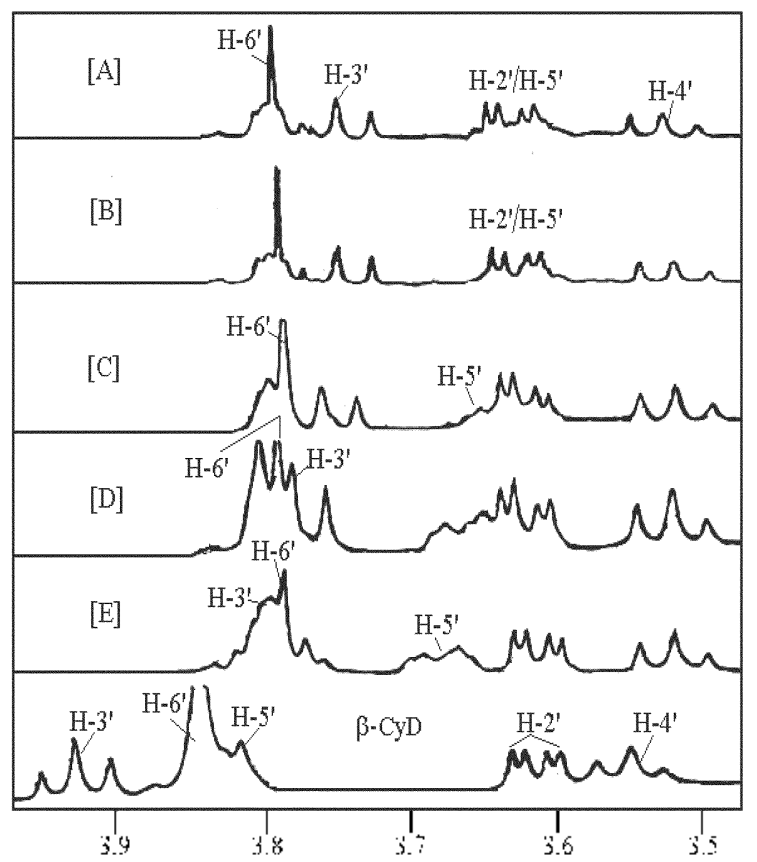

Figure 2. Partial ${ }^{1} \mathrm{H}$ NMR (400 MHz) spectra showing signals for the protons of $\beta$-cyclodextrin, in the absence as well as in the presence of venlalaxine hydrochloride.

of $\mathrm{H}-3^{\prime}$ and $\mathrm{H}-5^{\prime}$ located inside the $\beta$-CD cavity. Expansions of part of the spectra showing $\beta$ CD protons in the presence as well as in the absence of venlafaxine hydrochloride are shown in Figure 2, while their chemical shift change data is given in Table 1. These upfield shift changes in the inner $\beta$ CD cavity protons can only be explained in term of ring current effect of aromatic ring entering the host cavity and thus confirms the formation of VEN- $\beta$-CD complex. ${ }^{10.11}$ The higher magnitude for $\Delta \delta_{1-s^{\prime}}$ compared to $\Delta \boldsymbol{d}_{1-y^{\prime}}$ values may
Table 1. 'H NMR (400 MHz) chemical shift change $(\Delta \delta)$ values for the p-cyclodextrin $(\mathrm{H})$ protons in the presence of venlafaxine hydrochloride $(\mathrm{G})$ in $\mathrm{D}, \mathrm{O}$ al $25^{\circ} \mathrm{C}$. [II] was kept conslanl at $20 \mathrm{mM}$

\begin{tabular}{ccccccc}
\hline Sample & {$[\mathrm{G}] \mathrm{mM}$} & $\mathrm{H}-2^{\prime}$ & $\mathrm{H}-3^{\prime}$ & $\mathrm{H}-4^{\prime}$ & $\mathrm{H}-5^{\prime}$ & $\mathrm{H}-6^{\prime}$ \\
\hline $\mathrm{A}$ & 40.0 & 0.019 & -0.177 & -0.018 & $\#$ & -0.046 \\
$\mathrm{~B}$ & 31.8 & 0.017 & -0.174 & -0.026 & $\#$ & -0.052 \\
$\mathrm{C}$ & 25.4 & 0.010 & -0.167 & -0.028 & $\#$ & -0.057 \\
$\mathrm{D}$ & 12.6 & 0.007 & -0.146 & -0.026 & -0.156 & -0.052 \\
$\mathrm{E}$ & 8.00 & 0.001 & -0.128 & -0.005 & -0.141 & -0.057 \\
\hline
\end{tabular}

Negrative values indicale uplield shifts. Note; $\#$ could not be determined due to overlap of $[1-5$ ' signals with $] \mathrm{l}-2$ ' o[ $\beta-\mathrm{CI})$

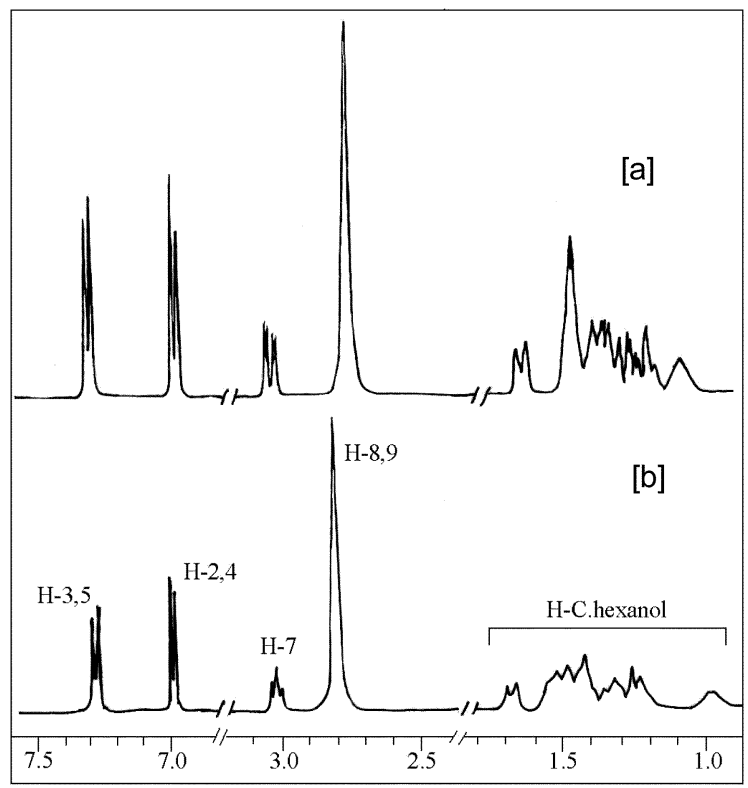

Figure 3. $\wedge$ part of 'HI NMR spectra showing variation in the signals of venlafaxine hydrochloride protons [a] venlataxine hydrochloride alone [b] VEN- $\beta$ CD mixture.

be due to the penetration of aromatic guest from narrow rim of $\beta \mathrm{CD} .^{! 2}$

Figure 3 shows the chemical shift changes in venlafaxine hydrochloride proton signals in the presence of $\beta$-CD. The pattern of the spectral region containing venlafaxine hydrochloride signals, in the spectra of mixtures of venlafaxine hydrochloride and $\beta$ C.D. remained more or less unchanged because concentration of the host was kept constant during titration. Generally, all the protons of the guest and not only the part that enters the $\beta \mathrm{CD}$ cavity, show chemical shift changes upon complexation with CDs.

The association constant $\left(K_{0}\right)$ of the complex was determined to be $234 \mathrm{M}^{-1}$ by using the Benesi-Hildebrand (Hanna-Ashbaugh) treatment. ${ }^{13}$

$$
1 / \Delta \delta=1 /\left(K_{\mathrm{n}} \Delta \delta_{\max }[\mathrm{G}]_{11}\right)+1 / \Delta \delta_{\max }
$$

A plot of $1 / \Delta \delta$ against $1 /[G]_{0}$, as a double reciprocal plot was found to be linear, confirming $1: 1$ Venlafaxine hydrochloride- $\beta$-CD complex stoichiometry, with a slope 1/ $K_{\mathrm{b}} \Delta \delta_{\max }$ and intercept $1 / \Delta \delta_{\max }$ (Figure 4$)^{1.3 .14}$ 


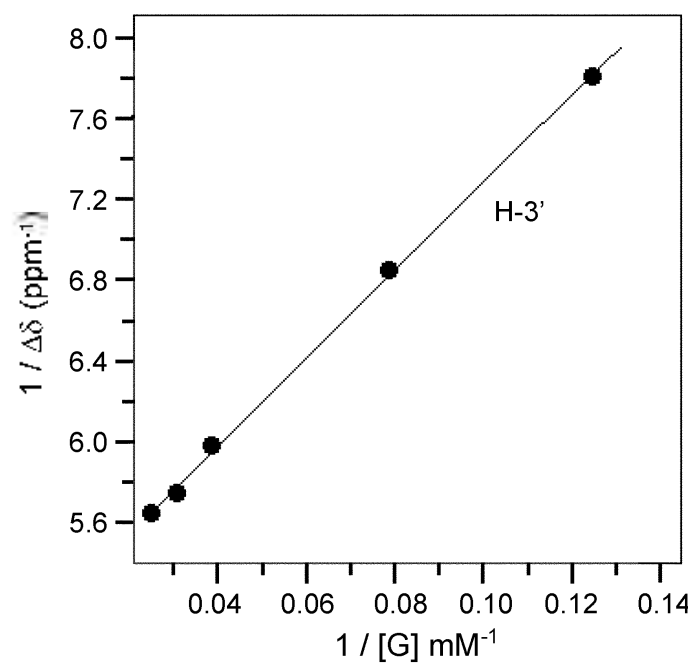

Figure 4. Illustration of the Benesi-f Iildebrand Data Treatment. The data from Table are plotted as a double reciprocal plot. A least squares fitting of this data gives $1 / \Delta \hat{\phi}_{\mathrm{mux}}=5.10105 \mathrm{ppm}{ }^{\prime}$ and 1 i $K_{\mathrm{il}} \Delta \delta_{\text {inal }}=21.76794 \mathrm{mM} \mathrm{ppm}{ }^{-1}$. I lence the Benesi-I lildebrand treatment gives $K_{\mathrm{i}}-234 \mathrm{M}^{-1}$.

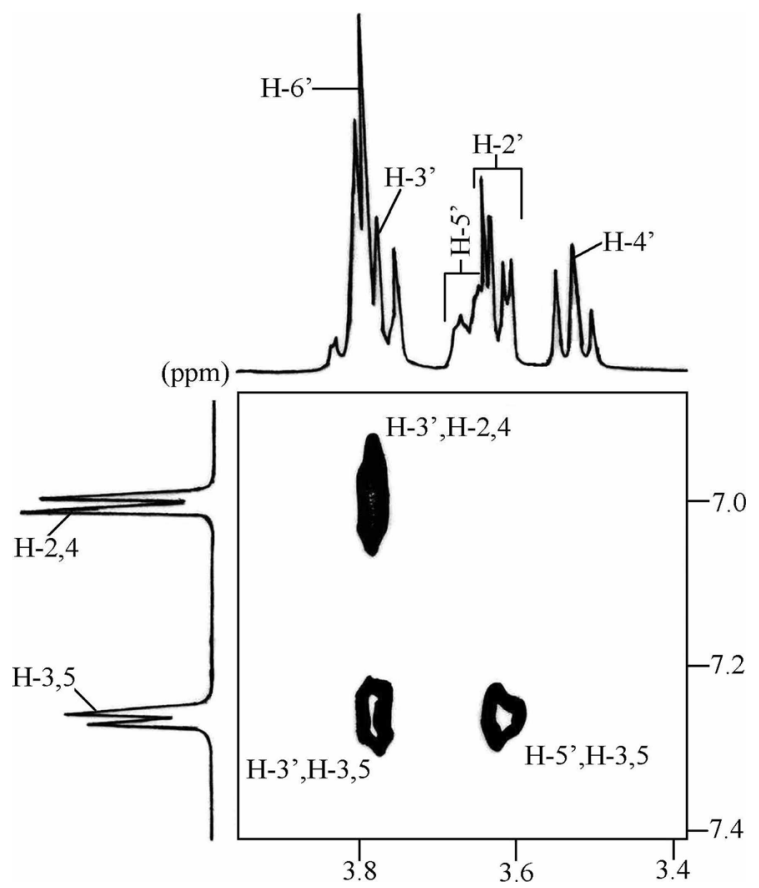

Figure 5. A section of 2D ROESY spectrum $(400 \mathrm{MHz})$ of the $1: 1$ mixlure of venlataxine hydrochloride wilh $\beta$ (C) (II), in 13,0 at 25 "C under spin lock condition with mixing time $500 \mathrm{~ms}$, showing cross peaks between aromatic protons and $\beta$-CD protons.

In order to clearly establish the structure of the VEN- $\beta-$ CD inclusion complex, ROESY experiment was performed on 1:1 mixture of venlafaxine hydrochloride and $\beta-C D$. The results are displayed in Figure 5; a set of intermolecular interactions is observed between $\mathrm{H}-3^{\prime}$ and $\mathrm{H}-5^{\prime}$ resonances of $\beta-\mathrm{CD}$ and aromatic ring protons, thus confirming the penetration of only aromatic ring into the host cavity. No cross peaks between the $\beta \mathrm{CD}$ cavity protons and aliphatic<smiles>COc1ccc(C(CN)C2(O)CCCCC2)cc1</smiles>

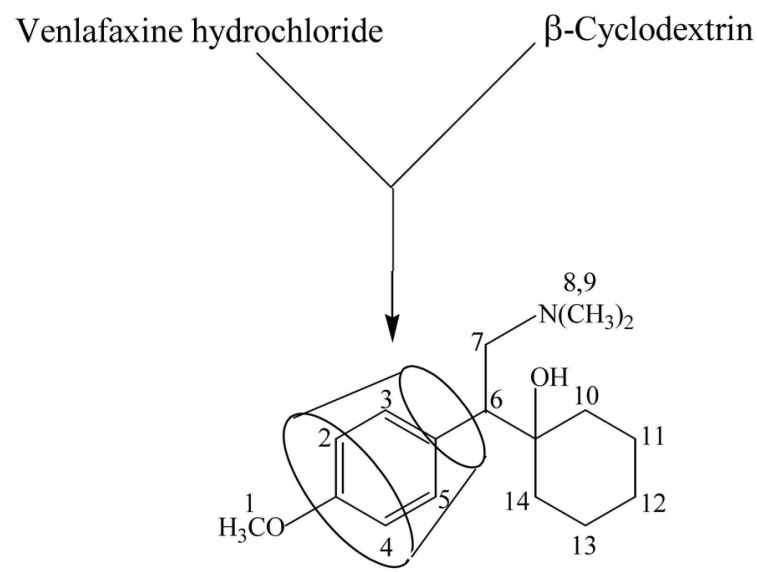

Figure 6. A plausible structure proposed for venlafaxine hydrochloride- $\beta$-CIs complex.

protons of venlafaxine hydrochloride were observed. Moreover, the $\mathrm{H}-3,5$ protons of aromatic ring showed connections with $\mathrm{H}-3^{+}$and $\mathrm{H}-5^{\prime}$ of $\beta$-CD while $\mathrm{H}-2,4$ showed cross peaks only with $\mathrm{H}-3$ ' suggesting the penctration of aromatic ring from primary rim of $\beta-\mathrm{CD}$ cavily. The structure proposed for the venlafaxine hydrochloride-f-CD complex is shown in Figure 6.

\section{Conclusion}

The detailed NMR spectroseopy study of venlafaxine hydrochloride in the presence as well absence of $\beta C D$ in solution confirmed the formation of $1: 1$ inclusion complex, resulting by the penetration of aromatic ring into the $\beta C D$ cavity from narrow rim side as evidenced by ROESY spectrum. The association constant $\left(K_{\mathrm{a}}\right)$ of the complex was determined to be $234 \mathrm{M}^{-1}$.

Acknowledgements. We wish to express our appreciation to Mr. Nikhil Deva, Cadila Pharmaceuticals, India for providing gift sample of venlafaxine hydrochloride and a very special thanks to Prof. Daniel O'Leary University of California, Los Angeles, for help in obtaining NMR spectra. Thanks are also extended to Prof. M.P. Willianson, Department of Molecular Biology and Biotechnology, University of Sheffield, UK, in obtaining COSY spectra.

\section{References}

I. Maj. J.; Rogor, Z. J. Nemal Tramshn 1999, I06, 197-211.

2. Schneider, II. J.; Flacket, F; Rudiger, V. Chem. Rev. 1998. 98 , $1755-1785$ 
3. Szejtli, J. Cyclodextrin Technology; Kluwer Academic Publishers: 1988; pp $81-83$.

4. Szejtli, J. Medicinal Applications of Cyclodextrins in Medicinal Research Review 1994, 14, 364.

5. Inoue, Y, NuR Studies of the Structural and Properties of Cyclodextrins and Therr Inclusion Complexes in Anmual Reports on NMR Spectroscopy; Academic Press: London, 1993; pp 59-101.

6. Connors, K. A. Chent. Rev. 1997, 97, 1325-1357.

7. Neuhaus, D.; Williamson, M. The Niclear Overhauser Effect in Structural and Conformational Antabsis; VCH Publishers: New York, $1989 ; \mathrm{p} \mathrm{I.}$

8. Ali, S. M.; Asmat, F.; Maheshwari, A. II Farmaco 2004, 59, 835838.
9. Ali, S. M.; Asmat, F.; Maheshwari, A. IL Farnaco 2005, 60,445449.

10. Demarco, P. V.; Thakkar, A. L. J. Chem. Soc. Chem. Conmtift. $1970,2-4$.

11. Rekharsky, M. V; Goldberg, R. N.; Schwarz, F. P.; Tiwari, Y. B.; Ross, P. D.; Yamashoji, Y.; Inoue, Y. J. Am. Chem. Soc. 1995, 117, $8830-8840$.

12. Nakajima, T.; Sunagawa, M.; Hirohashi, T.; Fujioka, K. Chen. Pharn. Btill. 1984, 32, 383-400.

13. Hanna, M. W; Ashbaugh, A. L. J. Phys. Chem, 1964, 68, 811816.

14. Benesi, H. A.; Hildebrand, J. H. J. Am. Chem. Soc. 1949, 7l, $2703-2702$. 